\title{
27e've been dancing in the shadows for far too long
}

Secret to success. Never say I can't, say I'll try to figure it out. Never say I don't have time. Be upfront and express timelines and deliverables clearly. Finally never express problems alone, do your best to present a solution with teamwork.

Information technology in India is an industry consisting of two major components: IT services and business process outsourcing (BPO). The sector has increased its contribution to India's GDP from $1.2 \%$ in 1998 to 7.5\% in 2012. ["Indian IT-BPO Industry". NASSCOM. Retrieved 15 December 2012.]

The true Buddha is silent, were the words told to me on numerous occasions by a wise Hungarian professor. How true these words were only began to resonate when I realized that the louder I spoke the less observant the audience. The weight in performance, in aptitude in a manner unnoticed has the advantage that the less noticeable one is as a threat to whatever, a job position or as an adversary the freer one is to continue with one's task.

With the advent of the millennium, like a silent ninja India struck the world with its capabilities with respect to information technology. No one saw us coming and now in NASA, 36\% or almost 4 out of 10 scientists are Indians. (See. http://timesofindia.indiatimes.com/india/36-of-scientists-at-NASA-are-Indians-Govtsurvey/articleshow/2853178.cms). Here we are seventeen years later stronger than ever:

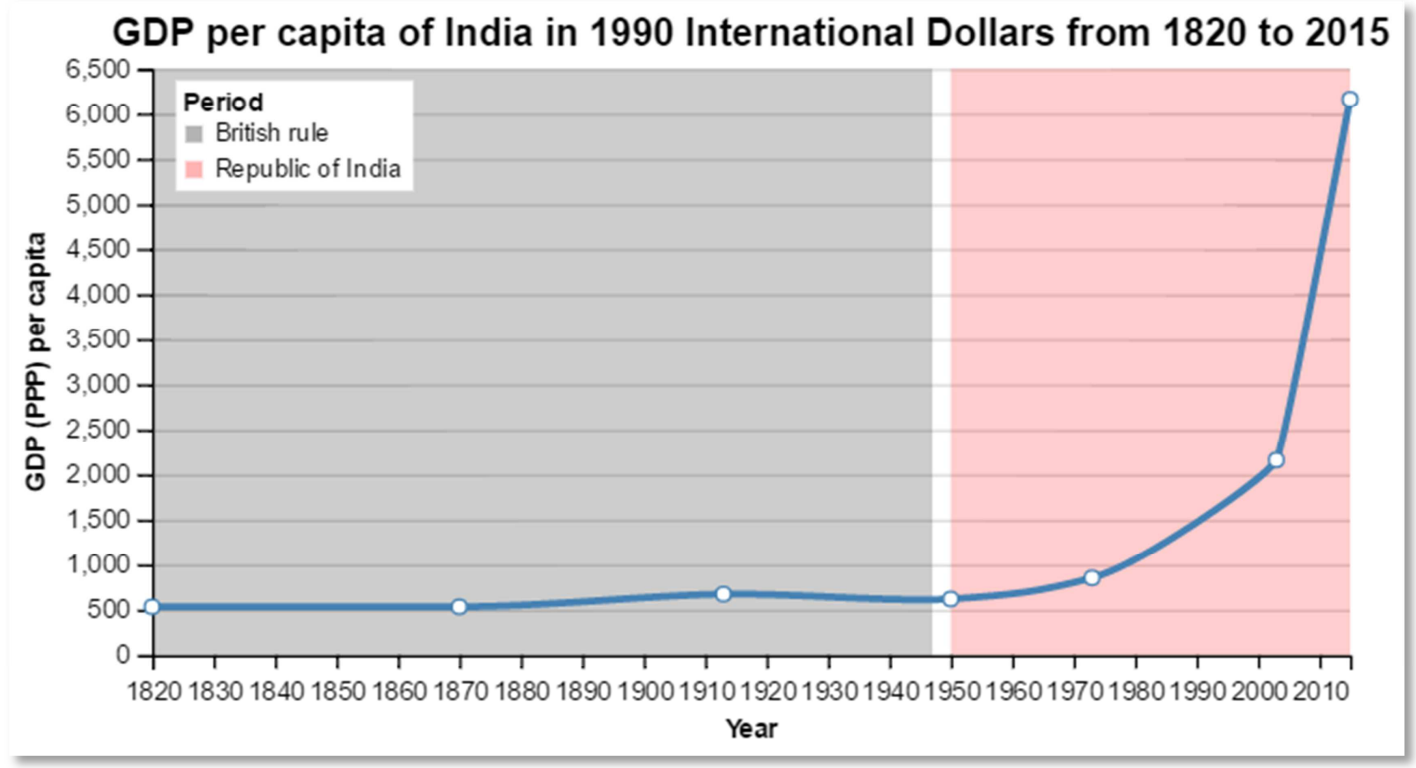

Figure 1: https://en.wikipedia.org/wiki/Economy_of_India

Intellectual Trojans, we are the propellant in every major global IT-titan, with 34\% employees at Microsoft, $28 \%$ at IBM, $17 \%$ at Intel and $13 \%$ at Xerox.

The game is one of chess, Nash-like where the best outcome is only obtainable when we simultaneously do what's best for ourselves and the group as a whole. (See. https://en.wikipedia.org/wiki/Nash_equilibrium). This is difficult on a mental and physiological level as it goes against the grain of self-interest, however if mastered, can lead to much overall success. If we are to position ourselves as global leaders; it is imperative that we follow this strategy and lookout not only for ourselves but ourselves and India in simultaneity. 
The 'flamboyant' superpower China, Cīna as it appears in the Mahābhārata, written in the 5th century BC, is running alongside in a race, the outcome of which is critical in the way of the political ambience that will be experienced for decades to come. With up to 20,000 refugees of Tibet currently living in Nepal, plans to build a railway paving easy access to China under Everest being considered

http://www.telegraph.co.uk/news/worldnews/asia/mounteverest/11524428/China-Nepal-railway-with-tunnel-underMount-Everest-being-considered.html, and military roads being built on the border of India and China http://www.business-standard.com/article/current-affairs/india-moves-mountains-to-build-military-road-to-chinaborder-117040600050_1.html, the outcome sincerely needs to be a favorable one!

My opinion, gone are the days of war being one of armed forces and entire nations offering up troops from all facets of industry to the military. The war of this generation is likely to be one with battle lines being drawn by trade policies and applicable publishable results, simply put, the wars of this era is sure to have its small battles with the aim of pandering to the masses, but will weigh on the side of sheer economic-capabilities and trade relations thereof as its deciding measure. Distancing ourselves from all forms of 'primitive thinking' such as the belief that war is a means of conquer or previsions in the ideas of caste and race with empirical focus on advancement in thinking is the key. After all, who wants to associate themselves with a country that stones a woman to death for infidelity! (http://www.mirror.co.uk/news/world-news/woman-stoned-death-adultery-saudi-6912835).

This is where we come in, for we are efficacies of economic-capability. With every measurable step in innovation, technology and science, we aim to distinguish ourselves, and boy are we winning!! India triumphs in maiden Mars mission, sets record in space race http://www.reuters.com/article/us-india-mars-idUSKCN0HJ05J20140924, are just some of the notably historical headlines imprinted into the annals of our entire civilization. The importance of this achievement drew conclusions to the world that India is not only a force to be reckoned with, but also the most accomplished and outright most capable country in Asia. After a failed joint mission to Mars by Russia and China, with China failing even to leave earth's orbit! Our Indian ninjas have proven a point to even Japan, a notable addition to the list adversaries that failed this race.

So what do we do as a cog in this grandiose Nash like game? Learn with the aim of advancing (yourself or your duty), Teach in a manner consistent with vidya dhanam. Be not prudish with innovation, as software engineers publish your ideas and incremental solutions and achievements on GitHub and the like. I ask you now, who amongst us will aim to be the next Pranav Mistry of our generation? (See.

https://www.ted.com/talks/pranav_mistry_the_thrilling_potential_of_sixthsense_technology ). Who amongst us will aim to be the next Ramanajum? (https://en.wikipedia.org/wiki/Srinivasa_Ramanujan ). The next Sir C.V Raman, without whom any form of pathological diagnosis of disease would be impossible, or the next Satyendra Nath Bose?

Let's not over-concern ourselves with raises and hikes in a manner proving to be a disservice only to ourselves. Keeping in theme with a fundamental software principle of separation of concerns, surely we must also separate the concerns of career growth and salary, for convoluting the two has the dire disadvantage of obtaining neither. Please don't mistake me, we all have families to protect and currency is thus the means. I only aim to convey that currency should not be the only propellant for your work. Seek out every notable problem in our country that can be resolved by an idea, and if all it takes for you to present it is a mere upload to YouTube or an open source publication, then I humbly say that not doing so is a sin. Many of our comrades found a simple means of using a curved drum, a cone both made of aluminum and nothing but the sun to distill water from the sea so as to aide farmers during times of drought.

Take with you some final words: "VIDYA DHANAM SARVA DHANAT PRADHANAM". Meaning "Amongst all the riches and virtues of life, education is the supreme". Finally, we are Indians and no matter what, we truly belong to the most peace loving, and one of and if not the most capable version of persons this worldly civilization has had to offer, and the universe will remember it so. 


\title{
Letter to Einstein from: Satyendra Nath Bose
}

\author{
PHYSIES DEPALYMEAT: \\ Dnoce Univoroity.
}

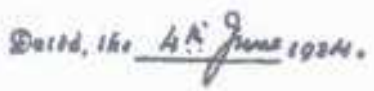

Qenforted fir. I have venkised to bued you

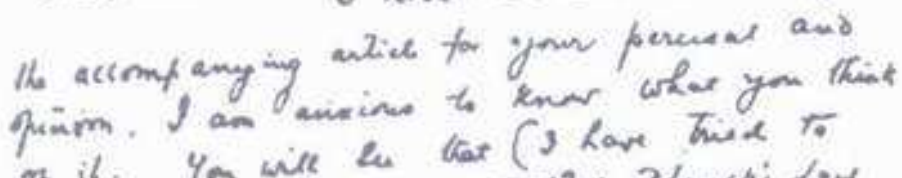
of il. You will en lat (J Rave think to detuce the coffenent $\frac{c^{3}}{c^{3}}$ ebits.mpamis,

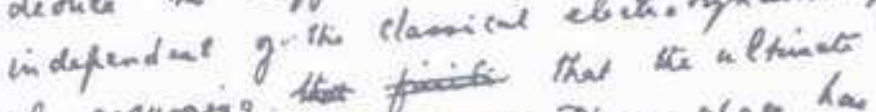

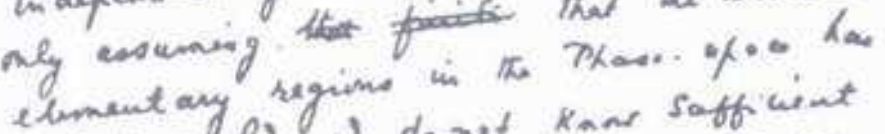
element ary segums din not kans safficient the in lise to biandele the pafer. If ya

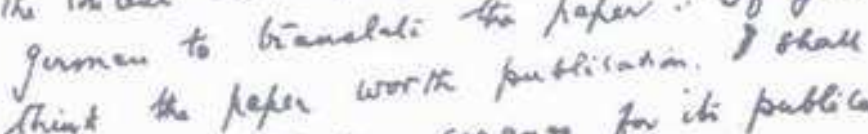
be giatefue of yon carrang for it pablecon in Zeitschift fin Phomeit. Whangh a

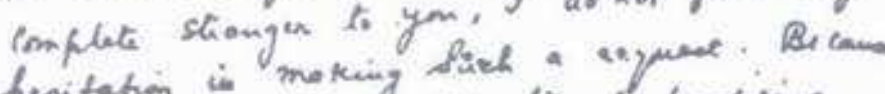

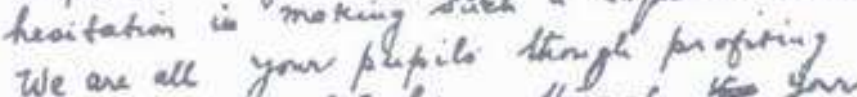
We are all your bieching. things the yor oniy by you leacheng" wher wher you

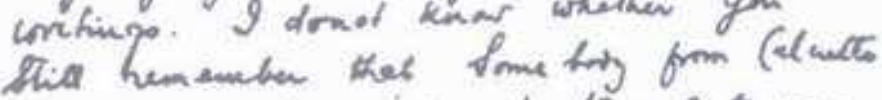

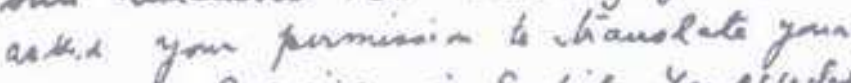
popers $n$ Relating in Eugkos. You acused t. the nqueot, th boot has his baw

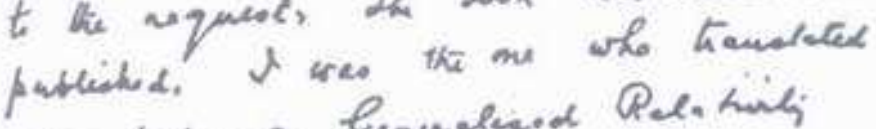

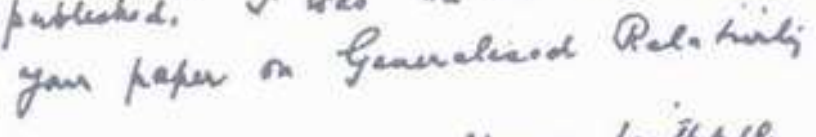

$$
\text { yours focingue }
$$

